$(1964-1970)$ S. Gnanalinqam (NASA) Jul. 


\section{EQUATORIAL IONOSPHERIC ABSORPTION DURING \\ HALF A SOLAR CYCLE (1964-1970)}

by

S. Gnanalingam*

Laboratory for Planetary Atmospheres

NASA/Goddard Space Flight Center

Greenbelt, Maryland

\section{ABSTRACT}

An extensive series of vertical incidence absorption measurements made at an equatorial station is analyzed in detail to provide information which will lead to a better understanding of the lower ionosphere. A quantitive empirical relationship is derived between absorption and 1-8 A solar flux for moderate levels of solar activity. It is shown that the threshold flux for D-region modification, at a solar zenith angle of $10^{\circ}$, is approximately $0.5 \times 10^{-3} \mathrm{erg} \mathrm{cm}^{-2} \mathrm{sec}^{-1}$. Attention is drawn to the incidence of days of high absorption even in the absence of solar X-ray activity. Available evidence points to variability of the order of $10-40 \%$ in the intensity of the

* NAS/NRC Resident Research Associate 
solar Lyman- $\alpha$ radiation as the most likely cause of these unusual, though infrequent, enhancements in absorption.

The influence of geomagnetic storms on equatorial absorption is found to be insignificant, both at solar minimum and at solar maximum.

In the diurnal variation of absorption, the maximum absorption occurs about 20-30 minutes after the time of minimum solar zenith angle. This time-lag is almost an order of magnitude larger than the time-lag expected on the basis of current estimates of the effective recombination coefficient for the lower ionosphere.

From the zenith angle dependence of the diurnal variation of absorption it is possible to predict the seasonal variation of the noon absorption. However, when this is done, significant departures from the predicted values are observed at the solstices. 


\section{INTRODUCTION}

The lower ionosphere at middle and high latitudes has been the subject of extensive study by diverse ground-based and rocket experiments. Over the years multi-frequency absorption measurements, L.F. and V.L.F. propagation studies, the partial-reflection technique, wave-interaction measurements and a multitude of rocket-borne experiments have all provided valuable information concerning the structure and formation of this region. In contrast, few of these techniques have been exploited at equatorial latitudes and, in consequence, little is known about the ionosphere below $110 \mathrm{~km}$. near the equator.

The present paper is an attempt to improve our understanding of the basic processes that control the electron density in the lower equatorial ionosphere, through an analysis of ionospheric absorption. The data used for the purpose is an extended series of absorption measurements made at Colombo, Ceylon $\left(06^{\circ} 54^{\prime} \mathrm{N}, 79^{\circ} 52^{\prime} \mathrm{E}\right.$, Dip angle $\left.5^{\circ} \mathrm{S}\right)$ during half a solar cycle from 1964 to 1970.

2. ABSORPTION DATA

Beginning with the IQSY, absorption and virtual height measurements were carried out daily, around noon, on the ordinary wave of several frequencies in the range 2.0 $5.4 \mathrm{MHz}$, by the vertical incidence pulse reflection (Al) method: and the diurnal variation of absorption was investigated on the three Regular World Days in each month. 
A limited series of measurements were also made on the frequency $1.33 \mathrm{MHz}$, for which special techniques were employed to extract the weak echoes from noise (Gnanalingam 1954). The precautions taken to ensure accuracy in the measurements, and the estimated limits of error have been discussed previously (Gnanalingam and Ratnasiri 1966). It is sufficient to state here that the absolute accuracy of the absorption data is better than $\pm 2 \mathrm{db}$.

Since the paper is concerned primarily with the lower ionosphere, only those observations made on frequencies reflected from the E-region are included in the analysis. The noon measurements on these frequencies $(2.0,2.2,2.6$ and $3.2 \mathrm{MHz}$ ) occupied a period of almost exactly one hour centered on $1200 \mathrm{hrs}$ Local standard Time. (At Colombo, Local Mean Time +10.5 min. = Local Standard Time = Universal Time $+5 \mathrm{hr} .30 \mathrm{~min}$.$) Fortunately this period coincides$ with one of the hourly intervals for which published solar X-ray data are available. The measurements on the individual frequencies have therefore been converted to a common frequency of $2.2 \mathrm{MHz}$ and their mean value is taken as the daily noon absorption index. The conversion factors used in this process of normalization were determined from the variation of absorption with frequency, which was assumed to be of the form

$$
L(f)=\text { const } \frac{1}{\left(f+f_{L}\right)^{n}}
$$


where $L(f)$ is the absorption on frequency $f$; and $f_{L}$ is the electron gyro-frequency about the longitudinal component of the earth's magnetic field (Colombo is just outside the region where the quasi-transverse approximation is applicable to vertical propagation of the frequencies employed in the present measurements: hence the use of the expression $1 /\left(f+f_{L}\right)^{n}$ instead of $1 / f^{n} \cdot f_{L}=0.093 \mathrm{MHz}$ at $100 \mathrm{~km}$ )。 The index ' $n$ ' was deduced from the monthly median values of absorption which were averaged, for the purpose of statistical smoothing, over groups of months according to season and over groups of years according to solar activity. The final values of ' $n$ ' are given in Table 1 . 3. ABSORPTION IN THE D-REGION BELOW $90 \mathrm{KM}$

If the greater part of the absorption occurred below the level at which the refractive index departs appreciably from unity, it follows from the magneto-ionic theory that the value of the index ' $n$ ' woúld be approximately equal to 2 (the effective collision frequency being less than the angular wave frequency over the range of altitudes which contribute significantly to the absorption, on the frequencies used in the present experiments). The fact that the index is much less than this value indicates that a substantial part of the absorption takes place near the reflection level.

One of the objectives of making absorption measurements on several frequencies reflected from the E-layer is to isolate the fraction of the absorption that occurs in the 
D-region, well below the reflection level, and hence obtain information on the changes that take place in this region. Various analytical methods, based on assumed models of the E-layer, have been developed for the purpose of resolving absorption data in this manner (Jaeger 1947, Bibl and Rawer 1951).

Ideally, one would like to be able to derive the electron density distribution of the lower ionosphere from groundbased absorption measurements. But, the absorption of a radio wave is a function of both the electron density as well as the collision frequency, so that the individual effects due to changes in these quantities cannot be readily separated. However, laboratory measurements have proved that, in a weakly ionized gas, the electron collision frequency is proportional to the gas pressure; and this has enabled the collision frequency distribution in the ionosphere to be computed from atmospheric pressure measurements (Phelps 1960).

Assuming such a distribution, Beynon and Rangasamy (1969) and Rangasamy (1971) have developed a method for the derivation of electron density profiles down to $60 \mathrm{~km}$. from absorption and virtual height measurements alone. Although profiles derived by this method, based as they are on the solution of a system of integral equations of limited number, are not unique, they have been found to be in fair agreement with the profiles measured, under similar conditions, by more direct methods. 
A profile deduced from ground-based absorption measurements on frequencies in the range $2-3.5 \mathrm{MHz}$, which are reflected from levels around $100 \mathrm{~km}$., will not necessarily be accurate at altitudes below $80 \mathrm{~km}$ because the contribution from this region to the total absorption is relatively small. In the case of the equatorial ionosphere, this is the very region for which reliable results have been obtained from the few rocket-borne propagation experiments that have hitherto been conducted near noon (Kane 1969, Aikin, Goldberg, Somayajulu and Avadhanulu 1972, Somayajulu et al 1971). Hence, by combining ground-based measurements with the results of rocket experiments, a significant improvement in the accuracy of the overall profile can be achieved.

A profile derived in this manner (Gnanalingam and Kane 1972) for noon at the equinoxes $\left(x=10^{\circ}\right)$ under non-flaring solar maximum conditions (the mean 1-8 $\AA$ solar $\mathrm{X}-\mathrm{ray}$ flux being $0.4 \times 10^{-3}$ ergs $\mathrm{cm}^{-2} \mathrm{sec}^{-1}$ ), is shown in Fig. 1. The absorption and virtual height resulting from the profile are compared with the measured values in Table 2 . It will be noted that only $40 \%$ of the absorption on $2.2 \mathrm{MHz}$ occurs below $90 \mathrm{~km}$. The greater part of it occurs in a narrow altitude range of about $6 \mathrm{~km}$. immediately below the reflection level (that is the level at which the wave frequency equals the plasma frequency).

The electron density distribution at sunspot minimum cannot be derived in the same way because rocket-borne 
measurements are not available for this epoch of the solar cycle. However, it is possible to estimate the order of magnitude of the decrease in electron density between sunspot maximum and sunspot minimum from the solar-cycle variation of absorption. This is discussed in section 4.1 . 4. THE VARIATION OF ABSORPTION WITH SOLAR ACTIVITY

4.1 Solar-cycle Variation

The increase of absorption with the general level of solar activity is illustrated in Fig. 2. A semi-annual seasonal variation is seen to be superimposed on a solarcycle increase which tracks the $10.7 \mathrm{~cm}$ solar flux. The dependence of absorption on solar activity is revealed more prominently in Fig. 3 where the seasonal variation has been smoothed out by taking 12-month running averages. Also shown in the figure is the solar control of the quiet-day absorption as represented by the mean of the ten days of least absorption in each month.

Fig. 3 shows that, during the ascending phase of the solar cycle, the absorption increases almost linearly with $10.7 \mathrm{~cm}$ flux. This dependence of absorption on the general level of solar activity may be expressed by the relationships:
(a)
$\overline{\mathrm{L}}_{2.2}=33.3+0.21\left(\mathrm{~S}_{\mathrm{a}}-70\right)$
$\mathrm{db}$
for the median absorption,
(b)

$$
\begin{aligned}
& \overline{\mathrm{L}}_{2.2}=30.6+0.21\left(\mathrm{~S}_{\mathrm{a}}-70\right) \\
& \text { for the quiet-day absorption, }
\end{aligned}
$$$$
d b
$$

where $\overline{\mathrm{L}}_{2.2}$ is the smoothed noon absorption in $\mathrm{db}$

$$
\text { normalized to } 2.2 \mathrm{MHz}
$$


and $S_{a}$ is the smoothed $10.7 \mathrm{~cm}$ solar flux at $1 \mathrm{~A} . \mathrm{U}$. in

$$
10^{-22} \mathrm{Wm}^{-2} \mathrm{~Hz}^{-1}
$$

At the peak of the solar cycle, the actual absorption is significantly higher than the values given by these expressions, and it does not vary with $10.7 \mathrm{~cm}$ flux in a regular manner. This indicates that a component of solar radiation, unrelated to the $10.7 \mathrm{~cm}$ flux, causes appreciable ionization only at sunspot maximum.

There is, of course, no reason to expect ionospheric absorption to be related to $10.7 \mathrm{~cm}$ solar flux. The flux itself does not produce any ionization. It is used here merely as an index of solar activity. One might just as well have used the sunspot number (Piggott 1959, Gnanalingam 1969) .

On the basis of present knowledge, the solar radiations that govern the formation of the lower ionosphere and produce ionization of sufficient magnitude to influence absorption are:

(a) Lyman- $\alpha$ which ionizes NO and is the dominant source of electrons in the altitude range $70-85 \mathrm{~km}$,

(b) 30-40 A radiation which ionizes $\mathrm{O}_{2}$ and $\mathrm{N}_{2}$, and exceeds by a factor of 2 the ionization produced by other radiations in the altitude range $88-94 \mathrm{~km}$. at solar zenith angles less $\operatorname{than} 30^{\circ}$,

(c) Lyman- $\beta$ which ionizes $\mathrm{O}_{2}$, the peak ion-pair production occurring at $103 \mathrm{~km}$ for overhead sun, 
(d) 40-100 A radiation which ionizes $\mathrm{O}_{2}$ and $\mathrm{N}_{2}$, substatially above $95 \mathrm{~km}$, and

(e) X-rays of wavelength less than $10 \AA$ which produce a broad maximum of ionization at altitudes below $95 \mathrm{~km}$, the actual altitude depending upon the hardness of the spectrum. Measurements of the absolute intensities of these radiations have been made at different levels of solar activity, but not in sufficient number to enable quantitative relationships to be established between them and the $10.7 \mathrm{~cm}$ flux. Published data seem to indicate that, when the $10.7 \mathrm{~cm}$ flux increases by a factor of 2 the intensities of the Lyman- $\alpha$ and Lyman- $\beta$ radiations increase by a factor of about 1.4 (Weeks 1967, Hall and Hinteregger 1970), the 40-60 $\mathrm{A}$ flux by a factor of the order of 5 and the slowly-varying component (that is the non-flaring component) of the $1-8 \stackrel{\circ}{A}$ flux by a factor of about 250 (Mandelstam 1965, Friedman 1970, Kreplin 1970). In the case of the 30-40 $\AA$ radiation, doubts have been cast (Hinteregger 1970) on the accuracy of the measurements that were made at sunspot minimum. Its solar-cycle variation can only be surmised by comparison with adjacent bands for which reliable measurements are available. The solar-cycle factor of this component is probably of the order of 20 .

Since the radiations responsible for the ion-production at various altitudes increase with solar activity at widely different rates, the electron density distribution, and 
hence the absorption, will change with $10.7 \mathrm{~cm}$ flux in a complicated manner. The apparently linear relationship revealed by Fig. 3 must therefore be regarded as fortuitous. We note from equation 3 that the quiet-day absorption decreases by a factor of 1.5 when the $10.7 \mathrm{~cm}$ flux falls from 140 units to 70 units. This decrease is attributable almost entirely to a reduction in electron density because the collision frequency below $95 \mathrm{~km}$ does not change significantly with solar activity (Thrane and Piggott 1966). The relative proportions of this decrease below and above $85 \mathrm{~km}$ cannot be evaluated until the solar-cycle variation of the No concentration, the effective recombination coefficient and the 30-40 $\AA$ flux are known. In the particular case where the NO distribution and the effective recombination coefficient remain constant, however, the electron densities below $84 \mathrm{~km}$ will fall by about $20 \%$ as a result of the decrease in the Lyman- $\alpha$ intensity: and it is readily shown that the average electron density in the altitude range $87-94 \mathrm{~km}$ must fall by a factor of about 2 in order to account for the decrease in absorption.

\subsection{Solar X-ray Control of Absorption}

The ionospheric effects induced by the large enhancements in X-ray flux accompanying solar flares are now well established. Much less is known about the influence of moderate increases in $\mathrm{X}$-ray activity. 
On the basis of a limited series of measurements made from the SR-1 satellite in 1960, close to sunspot maximum, Kreplin et al. (1962) concluded that sudden ionospheric disturbance phenomena occur when the solar X-ray flux below $8 \stackrel{\circ}{A}$ exceeds $2 \times 10^{-3} \mathrm{erg} \mathrm{cm}^{-2} \mathrm{sec}^{-1}$. Aikin (1971) has shown from a theoretical analysis of the ion-pair production in the D- and E-regions, in conjunction with a few rocket measurements, that the threshold $1-8 \AA$ flux for noticeable X-ray enhancement of the D-region, for $x=60^{\circ}$, is between $4 \times 10^{-4}$ and $4 \times 10^{-3} \mathrm{erg} \mathrm{cm}^{-2} \mathrm{sec}^{-1}$. A search of the literature has not revealed any other estimate of the minimum level of X-ray flux for D-region modification.

A quantitive measure of the sensitivity of the Dregion to small increases in $X-r a y$ flux is of prime importance to our understanding of D-region formation, because it affords a means of assessing the relative importance of the ionization sources. In particular, it can provide a rough estimate of the NO concentration, which has been the subject of much controversy. Bearing this in mind, a detailed analysis has been made of the variation of absorption with solar $x-r a y$ flux.

In recent years a large body of $\mathrm{X}-\mathrm{ray}$ data has become available through instruments mounted on satellites, principally the Solrad series of the U.S. Naval Research Laboratory. The detectors generally employed in these measurements are 
ionization chambers which, unfortunately, are also responsive to particle effects. Precautions are therefore necessary to detect the presence of particle interference and, as far as possible, filter out of the processed data the effects of this interference. This has been done in the case of the Solrad 9 measurements. The data series from the satellite begins in March 1968. The present analysis is based entirely on this data.

Preliminary inspection of the data indicated a strong correlation between absorption and 1-8 $\AA$ flux, even at moderate levels of flux, that is less than $3 \times 10^{-3} \mathrm{erg} \mathrm{cm}^{-2} \mathrm{sec}^{-1}$. A typical sequence of days is shown in Fig. 4: note particularly the period from 7 th May to 31st May. The correlation coefficient between absorption and X-ray flux was found to be significantly higher than that between absorption and either $10.7 \mathrm{~cm}$ flux or sunspot number.

In order to establish the quantitative relationship between absorption and 1-8 $\AA$ flux, the flux values were grouped into 0.5 millierg intervals, in ascending sequence up to 2.5 milliergs, and the absorption values on the corresponding days were averaged for months having approximately the same solar zenith angle. The results obtained for two zenith angles are shown in Fig. 5. The error bars represent the standard deviation of the individual values about the mean in each flux interval. They reflect the spread in the data. The $95 \%$ confidence limits of the means are typically $1 / 2$ to 


\section{PRECEDING PAGE BLANK NOT FILMED}

limited series of measurements made from the SR-1 satellite, during various phases of different flares, did not indicate a significant flare enhancement (Kreplin et al. 1962). In the case of the 30-40 $\AA$ flux, we have already drawn attention to the dominant role played by this radiation in the ionization of the 88-94 $\mathrm{km}$ altitude range, where most of the radio absorption takes place. It is quite conceivable, if not likely, that a major part of the absorption increase which has been attributed to the $1-8 \stackrel{\circ}{A}$ flux (for moderate activity) is, in fact, caused by the associated increase in the 30-40 $\mathrm{A}$. One cannot evaluate this, however, until systematic measurements are made of this most important component of solar radiation.

Another point that needs to be emphasized is the likelihood of there being some error in the absolute values of the 1-8 $\AA$ flux given in the published data. The reason is that the temperature and spectral distribution assumed for the solar $\mathrm{X}$-ray emitting regions, so as to calculate the flux from the ionization chamber current, may not be in accord with the true characteristics of these regions (Kreplin 1970, Horan 1970).

4.3 Absorption Enhancements in the Absence of X-ray Activity While the data proved that the day-to-day variability in absorption is controlled predominantly by solar X-rays, most probably in both the 1-8 $\AA$ and 30-40 $\AA$ bands, instances were noted of high absorption even in the absence of $\mathrm{X}-\mathrm{ray}$ 
activity. To explore this further, outstanding cases were identified when the noon absorption was significantly higher than the quiet-day level on all the radio frequencies, and the 1-8 $\AA$ flux (and presumably the 30-40 $\stackrel{\circ}{\mathrm{A}} \mathrm{lux}$ for which there is no data) was weak not only during the one-hour noon interval, but also for several hours before and after. Typical examples are indicated by arrows in Fig. 6 .

There did not appear to be any regularity in the incidence of these unusual days, nor were they correlated with geomagnetic disturbance. Furthermore, they were not associated with any abnormal changes in the sporadic-E layer. The virtual heights on all the frequencies were nearly the same as on the normal undisturbed days, but the variation of absorption with frequency seemed to be greater on the unusual days, indicating that the enhanced absorption was induced below $90 \mathrm{~km}$ (see section 3 ).

In order to clarify this point, the frequency dependence of the incremental absorption was determined. This is shown in Fig. 7. Each point represents the difference between the mean absorption on twenty of these unusual days, which occurred at different times of the year, and twenty matched control days of equal solar zenith angle. The latter were taken from among the ten days of least absorption in each month. 
The fact that the incremental absorption is inversely proportional to nearly the square of the frequency is strong evidence that the region below $90 \mathrm{~km}$ is the location of the enhanced absorption. The question arises whether this ionospheric effect originates in solar radiations other than $\mathrm{X}$-rays or in meteorological phenomena.

The stratospheric temperature at middle and high latitudes is known to undergo large fluctuations during the winter months, and there is some evidence that it correlates with the unexpectedly high absorption observed in winter (Bossolasco and Elena 1963, Shapley and Beynon 1965), generally referred to as the "winter anomaly". It has not been possible to determine whether a similar association exists at the equator between absorption and upper atmospheric meteorology because synoptic measurements of the latter are not available from low latitudes. However, it is now well established that the daily and seasonal variations of several meteorological parameters are smaller at tropical latitudes than at middle and high latitudes, as for example the temperature, pressure and ozone content (Smith et al. 1968, 1969, 1970, Prabhakara et al. 1971). The influx of electrons by meridional transport processes can also be ruled out at the equator. Hence it seems unlikely that the unusual increases in absorption are caused by meteorological effects.

Increases in the D-region ionization may be caused by electron precipitation. But, the associated equatorial 
ion-pair production, as deduced from a latitude survey conducted by Tulinov and Yakovlev (1969), is found to be much less, around noon, than that due to other solar radiations. Evidently, the only other possible mechanisms are variations in either the No concentration or the Lyman-alpha intensity, with time constants of the order of a day. The processes which control the NO distribution are not yet known with certainty (Aikin 1971). If the distribution were determined entirely by mixing, the NO concentration would remain substantially constant from day to day. If, on the other hand, photochemical reactions alone were the determining factor, the NO concentration would follow changes in the mesospheric temperature (Sechrist 1967), but this would be small at the equator for reasons which have been cited above. It would seem, therefore, that the unusual enhancements in absorption are most likely due to increases in the solar Lyman-alpha radiation which, estimated from the absorption measurements, can be as high as $40 \%$ of the background level. A $40 \%$ enhancement in the Lyman-alpha flux would not appear to be unreasonable when it is noted that its solar-cycle variation is of comparable magnitude.

\section{INFLUENCE OF GEOMAGNETIC ACTIVITY}

At latitudes near the auroral zone, geomagnetic disturbances are generally accompanied by striking increases in ionospheric absorption both during and after the disturbances (Piggott 1964). Ionization produced in the 
D-region by precipitated particles is believed to be the cause of the increased absorption.

The effects of geomagnetic activity on ionospheric absorption at middle latitudes is much less pronounced. Bourne and Hewitt (1968) have shown from a detailed statistical analysis of medium-frequency absorption data taken at several middle European latitudes that there is a positive short-term correlation between absorption and magnetic activity. But the relationship between the two quantities is not straightforward. The increased absorption seems to occur not on the storm day but 3-5 days after the storm. The reason for the time delay has not yet been satisfactorily explained.

In order to determine the influence of geomagnetic activity on equatorial absorption we have applied the superposed epoch method to the most intense magnetic storms that occurred both during the solar minimum years 1964-1965 and the solar maximum years 1968-1969. The criterion for selecting the storms was that $\Sigma K_{p} \geq 30$ at the peak of the storm. The results of the analysis are shown in Figures 8 and 9 respectively. They do not indicate a significant magnetic storm effect on equatorial absorption. 6. VARIATION OF ABSORPTION WITH SOLAR ZENITH ANGLE

One method of testing the theories of ion production and loss in the lower ionosphere is to derive from them electron density profiles appropriate to various solar zenith angles 
and to compare these profiles with the measurements. In the absence of measured electron density distributions, a simple test could be applied to the theory by examining the agreement between the virtual height and absorption measured at different solar zenith angles with the corresponding values computed from the theoretical profiles (Gnanalingam and Kane 1972). Measurements directed towards the study of the diurnal and seasonal variation of absorption may be used for this purpose.

\subsection{Diurnal Variation}

Figure 10 shows the diurnal variation of the virtual height and absorption on $2.2 \mathrm{MHz}$ derived from the measurements made on 15 undisturbed days in the equinoctial months of 1968, 1969, and 1970. An interesting feature is the delay of 20-30 minutes between the time of minimum solar zenith angle and the time of maximum absorption.

The time-lag from local noon in the diurnal variation of electron density in the altitude range $85-95 \mathrm{~km}$, where most of the $2.2 \mathrm{MHz}$ absorption takes place, can be evaluated from current estimates of the effective recombination coefficient. It is found to be an order of magnitude less than the observed time-lag in absorption. An explanation for the discrepancy must therefore be sought in terms of a diurnal variation in the collision frequency and thus in the atmospheric pressure. A 5-10\% variation in the pressure, with a delay of 20-30 minutes with respect to local 
noon is adequate to account for the observed delay in absorption.

Assuming that the diurnal variation may be expressed by a simple relationship between absorption, $\mathrm{L}_{2.2}$, and solar zenith angle, $\chi$, the formula which gives the best fit to the data is

$$
\mathrm{L}_{2.2}=52.4 \cos ^{0.8} \times \mathrm{db}
$$

for the equinoctial months at solar maximum. For the equinoctial months at solar minimum the relationship obtained is

$$
\mathrm{L}_{2.2}=35.7 \cos ^{0.9} \times \mathrm{db}
$$

The diurnal variation of absorption on a disturbed day is presented in Figure 11. Also shown in the figure is the variation in the $1-8 \stackrel{\circ}{A}$ solar $X-r a y$ flux deduced from the minute-by-minute data obtained by the NRL SOLRAD 9 satellite. Apart from the obvious flare effect, the figure reveals a close correlation between short-term increases in absorption and moderate enhancements in solar X-ray flux, even at large zenith angles.

\subsection{Seasonal Variation}

The seasonal variation of the undisturbed noon absorption is illustrated in Figure 12. The predicted seasonal variation is derived on the assumption that it 
has the same solar zenith angle dependence as the diurnal variation. Large deviations from the predicted values are evident at the solstices. The percentage deviation is approximately the same at both solar minimum and solar maximum. A fraction of this deviation is attributable to the semi-annual seasonal variation of the collision frequency (also shown in the figure) resulting from the atmospheric pressure variation (Groves 1971). The greater part of this apparent seasonal anomaly is most probably due to seasonal modification of the electron density profile caused by changes in the atmospheric composition.

Further progress in the interpretation of this seasonal anomaly must await systematic rocket measurements of the atmospheric composition at equatorial latitudes.

\section{CONCLUSIONS}

The principal characteristics of equatorial ionospheric absorption are as follows:

(a) During the ascending phase of the solar cycle, the noon absorption increases almost linearly with $10.7 \mathrm{~cm}$ solar flux. This dependence of absorption on the general level of solar activity may be expressed by the relationship

$$
\overline{\mathrm{L}}_{2.2}=30.6+0.21\left(\mathrm{~S}_{\mathrm{a}}-70\right) \mathrm{db}
$$

for the 12-month average quiet-day absorption, where $\overline{\mathrm{L}}_{2.2}$ is the smoothed noon absorption normalized to $2.2 \mathrm{MHz}$ and 
$\mathrm{S}_{\mathrm{a}}$ is the smoothed $10.7 \mathrm{~cm}$ solar at 1 A.U. in $10^{-22} \mathrm{Wm}^{-2} \mathrm{H}_{\mathrm{Z}}^{-1}$. At the peak of the solar cycle, the actual absorption is significantly higher than the value given by this expression, and it does not vary with $10.7 \mathrm{~cm}$ flux in a regular manner.

(b) At solar maximum, the day-to-day variation of noon absorption is strongly correlated with 1-8 A solar flux, even at moderate levels of flux, that is less than $3 \times 10^{-3}$ erg $\mathrm{cm}^{-2} \mathrm{sec}^{-1}$. The relationship between absorption and $1-8 \AA$ flux is

$$
\begin{aligned}
& \overline{\mathrm{L}}_{2.2}=44.7+(11.5 \pm 0.5) \sqrt{\mathrm{U}} \quad 0.4 \lesssim \mathrm{U} \lesssim 2.0 \\
& \text { for } X \simeq 10^{\circ}
\end{aligned}
$$

and

$$
\begin{aligned}
& \overline{\mathrm{L}}_{2.2}=37.0+(11.1 \pm 0.5) \sqrt{\mathrm{U}} \quad 0.4 \lesssim U \lesssim 2.0 \\
& \text { for } x \simeq 30^{\circ}
\end{aligned}
$$

where $\overline{\mathrm{L}}_{2.2}$ is the noon absorption normalized to $2.2 \mathrm{MHz}$ and $\mathrm{U}$ is the 1-8 $\stackrel{\circ}{\mathrm{A}}$ solar flux in milliergs $\mathrm{cm}^{-2} \mathrm{sec}^{-1}$. The threshold flux for D-region modification, at a solar zenith angle of $10^{\circ}$, is approximately $0.5 \times 10^{-3} \mathrm{erg} \mathrm{cm}^{-2} \mathrm{sec}^{-1}$.

(c) Days of high absorption occur even in the absence of solar X-ray activity. Available evidence points to variability of the order of $10-40 \%$ in the intensity of the solar Lyman- $\alpha$ radiation as the most likely cause of these unusual, though infrequent, enhancements in absorption. 
(d) Magnetic storms have a negligible effect on equatorial absorption both at solar minimum and at solar maximum.

(e) In the diurnal variation of absorption, maximum absorption occurs about 20-30 minutes after the time of minimum solar zenith angle. This time-lag is almost an order of magnitude larger than the time-lag expected on the basis of current estimates of the effective recombination coefficient for the lower ionosphere. Assuming that the diurnal variation could be expressed by a simple relationship between absorption and solar Zenith angle, the formulae which give the best fit to the data are

$$
\mathrm{L}_{2.2}=52.4 \cos ^{0.8} \times \mathrm{db}
$$

and

$$
\mathrm{L}_{2.2}=35.7 \cos ^{0.9} \times \mathrm{db}
$$

for the equinoctial months at solar maximum and solar minimum respectively.

(f) The seasonal variation of the quiet-day noon absorption exhibits significant departures from the values predicted from the zenith angle dependence of the diurnal variation. This apparent seasonal anomaly is most probably due to seasonal modification of the electron density distribution caused by changes in the atmospheric composition. The results of the present study, based as they are on a detailed analysis of a large body of accurate measurements, provide a stringent testing ground for models of the lower ionosphere. 


\section{ACKNOWLEDGEMENTS}

The author wishes to express his sincere thanks to A. C. Aikin and J. A. Kane for many helpful discussions. The assistance given by $R$. W. Kreplin and his staff at the Naval Research Laboratory, in supplying the necessary solar $\mathrm{X}-\mathrm{ray}$ data, is gratefully acknowledged.

The absorption measurements which form the basis of this paper were made by the staff of the Applied Physics Division, Ceylon Institute of Scientific and Industrial Research。 


\section{REFERENCES}

Aikin, A.C., "Ionization Sources of the Ionospheric D and E Regions", Proceedings of the COSPAR Symposium on Dand E-Region Ion Chemistry (to be published) 1971. Aikin, A.C., R.A. Goldberg, Y.V. Somayajulu and M.B. Avadhanulu, "Electron and Positive Ion Density Altitude Distributions in the Equatorial D Region", J. Atmos. Terr. Phys. (in press) 1972 .

Beynon, W.J.G., and S. Rangaswamy, "Model Electron Density Profiles for the Lower Ionosphere", J.Atmos. Terr. Phys. , 31, 891-903, 1969.

Bibl, K., and K. Rawer, "Les Contributions des Regions D et $\mathrm{E}$ dans les Mesures de l'Absorption Ionospherique", J. Atmos. Terr. Phys. , 23, 244-259, 1962.

Bossolasco, M., and A. Elena, "Absorption de la Couche D et Temper ature de la Mesosphere", Compt. Rend., 256, 4491-4493, 1963 .

Bourne, I.A., and L.W. Hewitt, "The Dependence of Ionospheric Absorption of MF Radio Waves at Mid-latitudes on Planetary Magnetic Activity", J. Atmos. Terr. Phys., 30, 1381-1395, 1968.

Friedman, H., "Observations of Solar Ionizing Radiations and Their Significance for the Eclipse-Ionosphere", Solar Eclipses and the Ionosphere, ed. M. Anastassiades, Plenum Press, 1970. 
Gnanalingam, S., "An Apparatus for the Detection of Weak Ionospheric Echoes", Proc. I.E.E., 101, Pt. III, 243248,1954 .

Gnanalingam, S., and P.A.J. Ratnasiri, "Ionospheric

Absorption Measurements at Colombo, Ceylon", Ann. de Geophys. , 22 $, 361-367,1966$.

Gnanalingam, S., "Ionospheric Absorption at Low Latitudes", Proceedings of the Third International Symposium on Equatorial Aeronomy, Vol. I, pp. 47-69, Physical Research Laboratory, Ahmedabad, India, 1969. Gnanalingam, S., and J.A. Kane, "Electron Density Profiles in Relation to Solar XUV Radiation and Ground-Based Radio Wave Absorption Measurements", (to be published), 1972 .

Groves, G.V., "Atmospheric Structure and Its Variations in the Region from 25 to $120 \mathrm{~km}$ ", Environmental Research Paper, No. 368, AFCRL-71-0410, 27 July 1971.

Hall, L.A., and H.E. Hinteregger, "Solar Radiation in the Extreme Ultraviolet and Its Variation with Solar Rotation", J. Geophys. Res., 75, 6959-6965, 1970. Hinteregger, H.E., "The Extreme Ultraviolet Solar Spectrum and Its Variation During a Solar Cycle", Ann. de Geophys., 26, 547-554, 1970 .

Horan, D.M., "Coronal Electron Temperatures Associated with Solar Flares"; Dissertation submitted to the Catholic University of America, Washington, D.C., 1970. 
Jaeger, J.C., "Equivalent Path and Absorption in an

Ionospheric Region", Proc. Phys. Soc., 59, 87-96, 1947.

Kane, J.A., "D Region Radio Measurements at the Magnetic

Equator", NASA-Goddard Report X-615-69-499, November 1969.

Kreplin, R.W., T.A. Chubb and H. Friedman, "X-ray and Lyman-Alpha Emission from the Sun as Measured from the NRL SR-1 Satellite", J. Geophys. Res., 67, 22312253,1962 .

Kreplin, R.W., "The Solar Cycle Variation of Soft X-Ray

Emission", Ann. de Geophys. , 26, 567-574, 1970.

Mandelstam, S.L., "X-Ray Emission of the Sun", Space Sci.

$\underline{\text { Rev. }, ~} \underline{4}, 487-665,1965$.

Phelps, A.V., "Propagation Constants for Electromagnetic

Waves in Weakly Ionized, Dry Air", J.Appl. Phys., 31 ,

$1723-1729,1960$.

Piggott, W.R., "The Calculation of the Median Sky Wave Field strength in Tropical Region", p. 33, H.M.S.O., London, 1959 .

Piggott, W.R., "Studies of Ionospheric Absorption" in Research in Geophysics Vo1. 1: Sun, Upper Atmosphere, and Space, M.I.T. Press, 1964.

Prabhakara, C., B.J. Conrath, L.J. Allison and J. Steranka, "Seasonal and Geographic Variation of Atmospheric Ozone Derived from Nimbus $3^{\prime \prime}$, NASA Technical Note TN D-6443, August 1971 . 
Rangaswamy, S., "The Electron Density Profile in the D and E Regions of the Equatorial Ionosphere", NASA-Goddard Report X-550-71-433, October 1971 .

Sechrist, C.F., "A Theory of the Winter Absorption Anomaly

at Middle Latitudes", J.-Atmos. Terr.Phys., 29, 113136, 1967 .

Shapley; A.H., and W.J.G. Beynon, "Winter Anomaly in

Ionospheric Absorption and Stratospheric Warmings", Nature, 206 $1242-1243,1965$.

Smith, W.S., J.S. Theon, P.C. Swartz, J.F. Casey and J.J. Harvath, "Temperature, Pressure, Density and Wind Measurements in the Stratosphere and Mesosphere", NASA Technical Reports TR R-288, TR R-316 and TR R-340, $1968,1969,1970$.

Somayajulu, Y.V., M.B. Avadhanulu, K. S. Zalpuri and S.C. Garg, "Some Preliminary Results of the Rocket Sounding of the D Region at the Geomagnetic Equator", Space Research XI, 1132-1137, Akademic-Verlag, Berlin, 1971 .

Thrane, E.V., and W.R. Piggott, "The Collision Frequency in the $\mathrm{E}-$ and D-Regions of the Ionosphere", J. Atmos. Terr. Phys., 28, 721-737, 1966.

Tulinov, V.F., and S.G. Yakovlev, "Contribution of Corpuscular Radiation to the Ionization of Ionosphere's D-Layer", Kosmicheskiye Issledovaniya, $\underline{7}, 122-126,1969$. 
Weeks, L.H., "Lyman-alpha Emission from the Sun Near Solar Minimum", Astrophys. J. (letters), 147, $1203-1205,1967$. 


\begin{tabular}{|c|c|c|c|}
\hline & $\begin{array}{c}\text { WINTER } \\
\text { (DEC. JAN.) } \\
\chi \simeq 29^{\circ}\end{array}$ & $\begin{array}{c}\text { EQUINOXES } \\
\text { (MAR. APR. } \\
\text { SEPT. OCT.) } \\
\chi \simeq 10^{\circ}\end{array}$ & $\begin{array}{c}\text { SUMMER } \\
\text { (JUNE, JULY) } \\
\chi \simeq 16^{\circ}\end{array}$ \\
\hline $1964 / 65$ & 1.04 & 1.12 & 0.91 \\
\hline $1966 / 67$ & 1.23 & 1.09 & 1.02 \\
\hline $1968 / 69 / 70$ & 1.18 & 1.02 & 0.99 \\
\hline
\end{tabular}

TABLE 1: INDEX ' $n$ ' IN THE EXPRESSION L $(f)=$ const. $\frac{1}{\left(f+f_{L}\right)^{n}}$ 


\begin{tabular}{|c|c|c|c|c|c|c|c|c|c|c|}
\hline \multirow[b]{2}{*}{$\begin{array}{r}\text { FREQUENCY } \\
(\mathrm{MHz})\end{array}$} & \multirow{2}{*}{$\begin{array}{c}\text { TRUE } \\
\text { HEIGHT } \\
(\mathrm{km})\end{array}$} & \multicolumn{2}{|c|}{ VIRTUAL HEIGHT } & \multicolumn{4}{|c|}{ COMPUTED ABSORPTION } & \multirow{2}{*}{$\begin{array}{c}\text { MEASURED } \\
\text { ABSORPTION } \\
\text { (db) } \\
\end{array}$} & \multicolumn{2}{|c|}{ COMPUTED } \\
\hline & & $\begin{array}{c}\text { Computed } \\
(\mathrm{km})\end{array}$ & $\begin{array}{c}\text { Measured } \\
(\mathrm{km})\end{array}$ & $\begin{array}{c}60 \mathrm{~km} \text { to } \\
90 \mathrm{~km} \\
(\mathrm{db})\end{array}$ & \begin{tabular}{|c|}
$90 \mathrm{~km}$ to \\
Refl. Level \\
(db)
\end{tabular} & $\begin{array}{c}\text { Phase } \\
\text { Innegral } \\
\text { Correction } \\
\text { (db) }\end{array}$ & $\begin{array}{l}\text { Total } \\
(\mathrm{db})\end{array}$ & & $\begin{array}{l}\% \text { Abs. } \\
\text { below } \\
90 \mathrm{~km}\end{array}$ & $\begin{array}{l}\text { \% Abs. } \\
\text { below } \\
85 \mathrm{~km}\end{array}$ \\
\hline $1.33^{*}$ & 92.741 & 96.8 & $96.5 \pm 1.5$ & 48.8 & 30.8 & 3.2 & 82.8 & $87 \pm 6$ & $59 \%$ & $45 \%$ \\
\hline 2.0 & 95.509 & 100.4 & $100.4 \pm 1.8$ & 24.8 & 31.3 & 1.5 & 57.6 & $57.2 \pm 2$ & $43 \%$ & $35 \%$ \\
\hline 2.2 & 96.190 & 101.3 & $101.3 \pm 1.9$ & 21.2 & 30.1 & 1.3 & 52.6 & $52.1 \pm 2$ & $40 \%$ & $32 \%$ \\
\hline 2.6 & 97.453 & 103.0 & $102.4 \pm 2.0$ & 16.0 & 28.5 & 1.0 & 45.5 & $44.7 \pm 2$ & $35 \%$ & $29 \%$ \\
\hline 3.2 & 99.096 & 105.4 & $104.6 \pm 2.2$ & 11.2 & 26.4 & 0.8 & 38.4 & $38.3 \pm 2$ & $29 \%$ & $24 \%$ \\
\hline
\end{tabular}

NOON MEASUREMENTS MADE ON DAYS WHEN THE 1-8A SOLAR X-RAY FLUX WAS LESS THAN $0.5 \times 10-3$ ERG $\mathrm{CM}^{-2} \mathrm{SEC}^{-1}$ IN THE EQUINOCTIAL MONTHS OF 1968, 1969, 1970. THE MEAN VALUES OF THE RELEVANT SOLAR CONDITIONS WERE: ZENITH ANGLE $10^{\circ}$, SUNSPOT NUMBER 85 AND 10-CM FLUX 135 UNITS.

* ON $1.33 \mathrm{MHz}$, MEASUREMENTS UNDER SIMILAR SOLAR CONDITIONS WERE AVAILABLE FOR ONLY 16 DAYS.

** LEVEL AT WHICH PLASMA FREQUENCY EQUALS EXPLORING WAVE FREQUENCY.

TABLE 2: MODEL PROFILE TESTED AGAINST 72 DAYS OF ACCURATE ABSORPTION MEASUREMENTS 


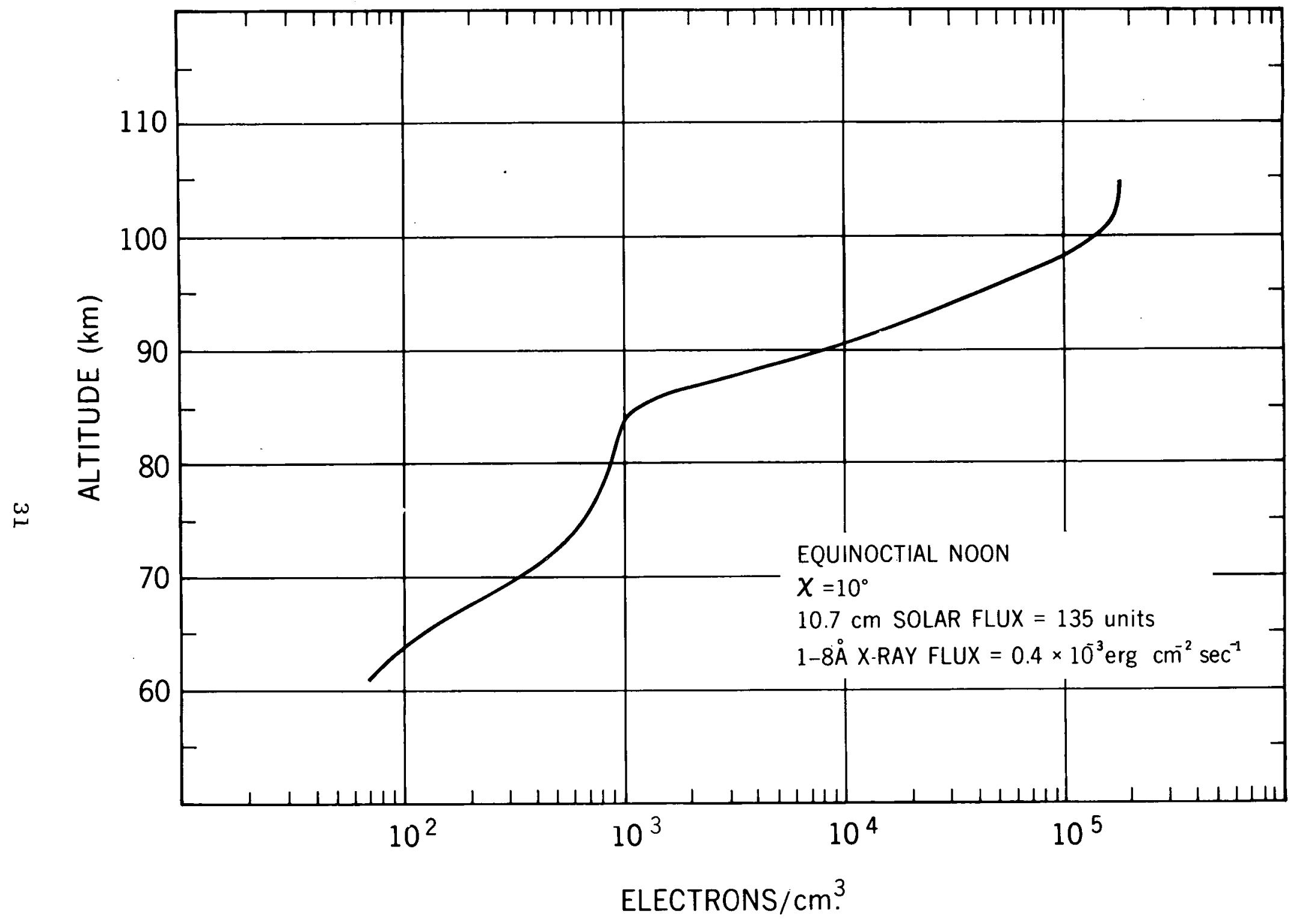

FIGURE 1: EQUATORIAL REFERENCE PROFILE 


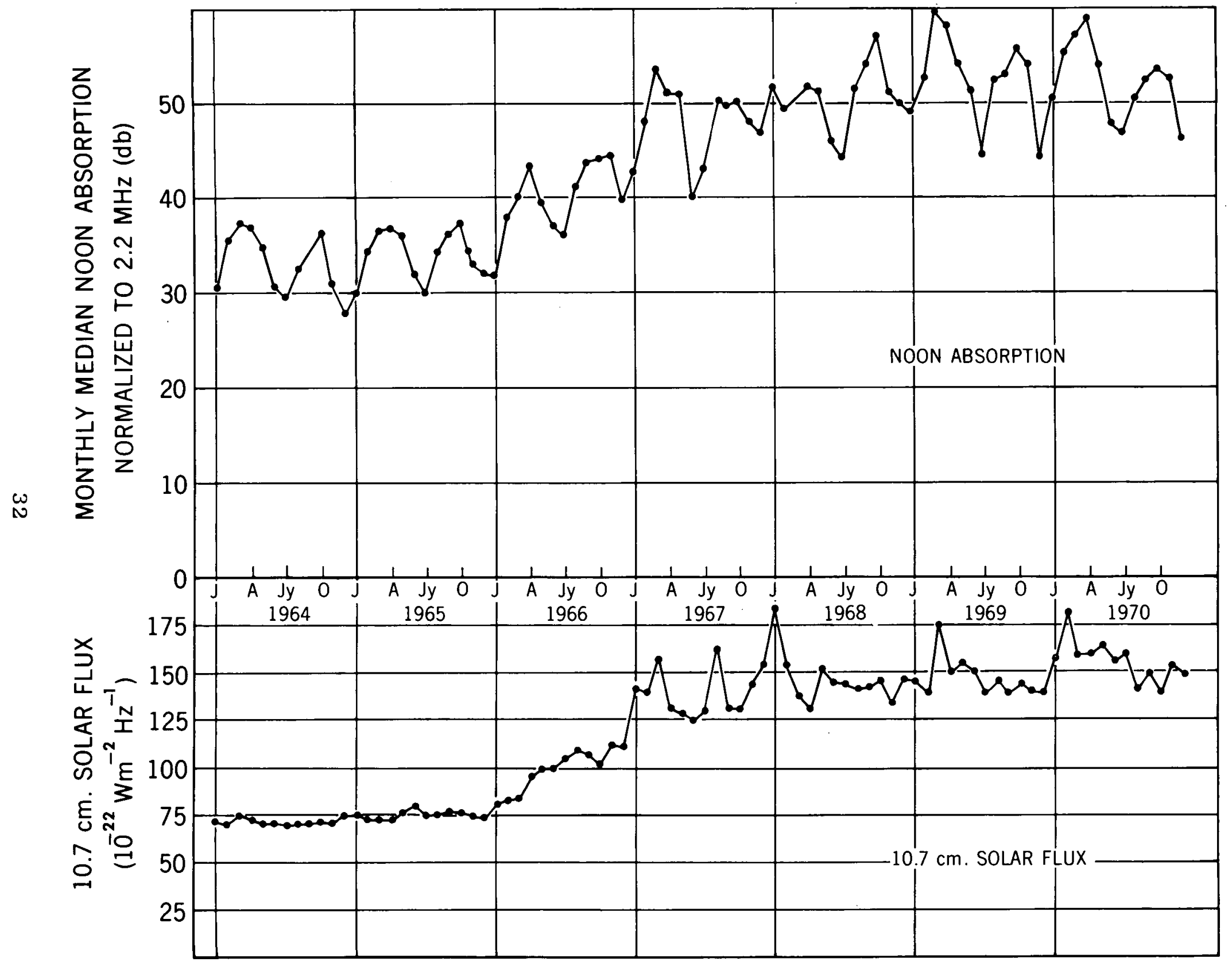

FIGURE 2: THE SOLAR-CYCLE VARIATION OF EQUATORIAL ABSORPTION 


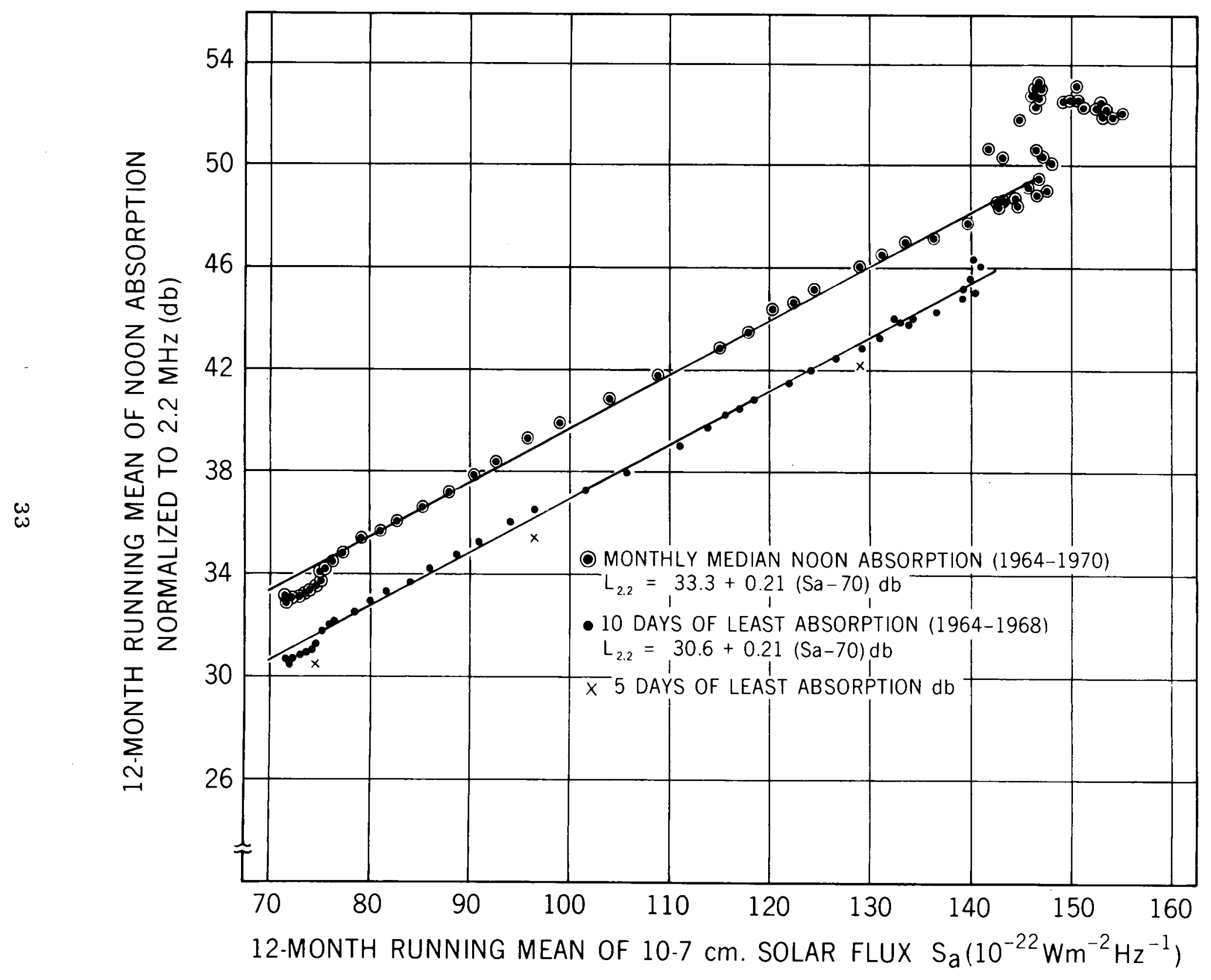

FIGURE 3: DEPENDENCE OF ABSORPTION ON THE GENERAL LEVEL OF SOLAR ACTIVITY 


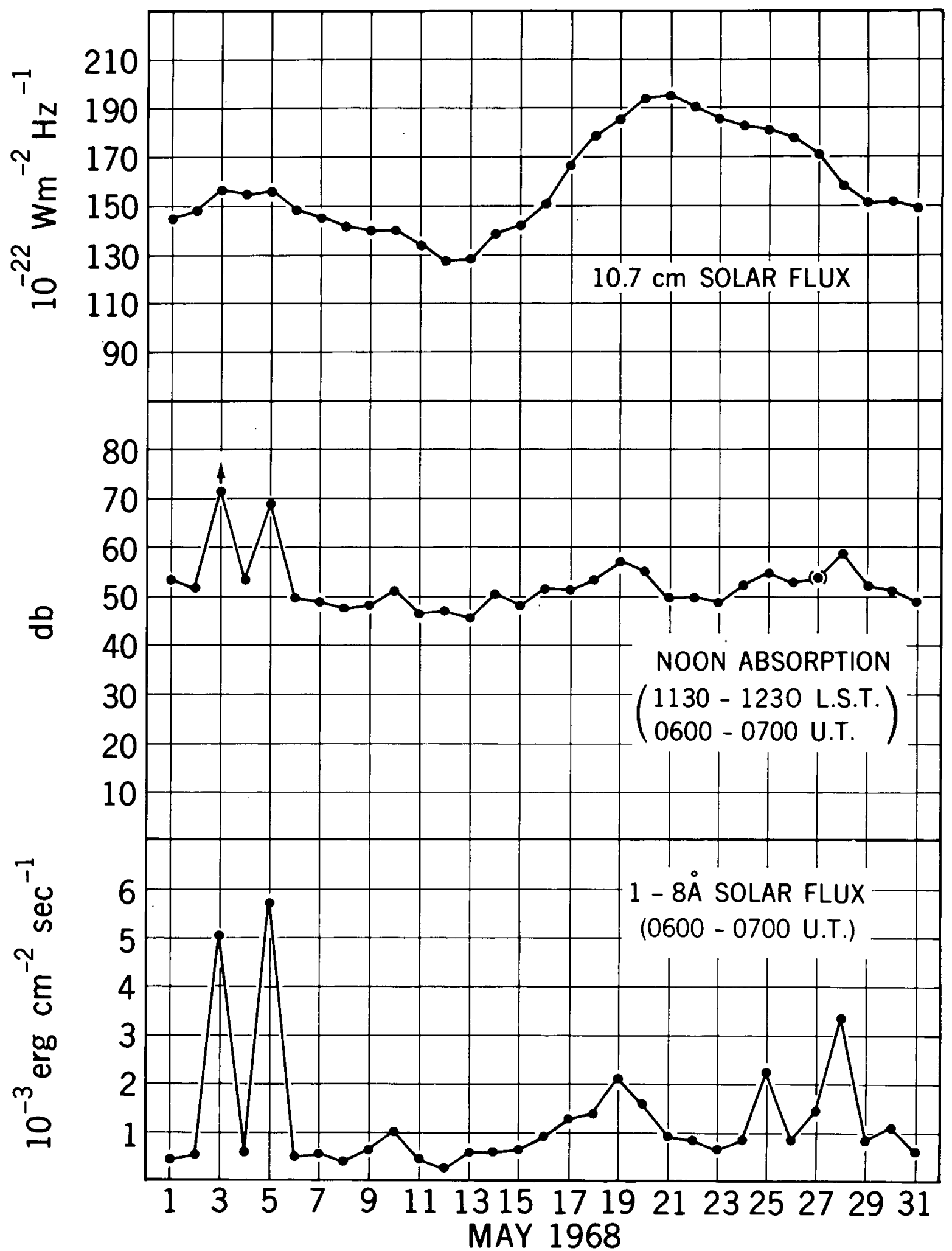

FIGURE 4: DAY-TO-DAY CORRELATION OF ABSORPTION WITH MODERATE

LEVELS OF SOLAR 1-8A FLUX 


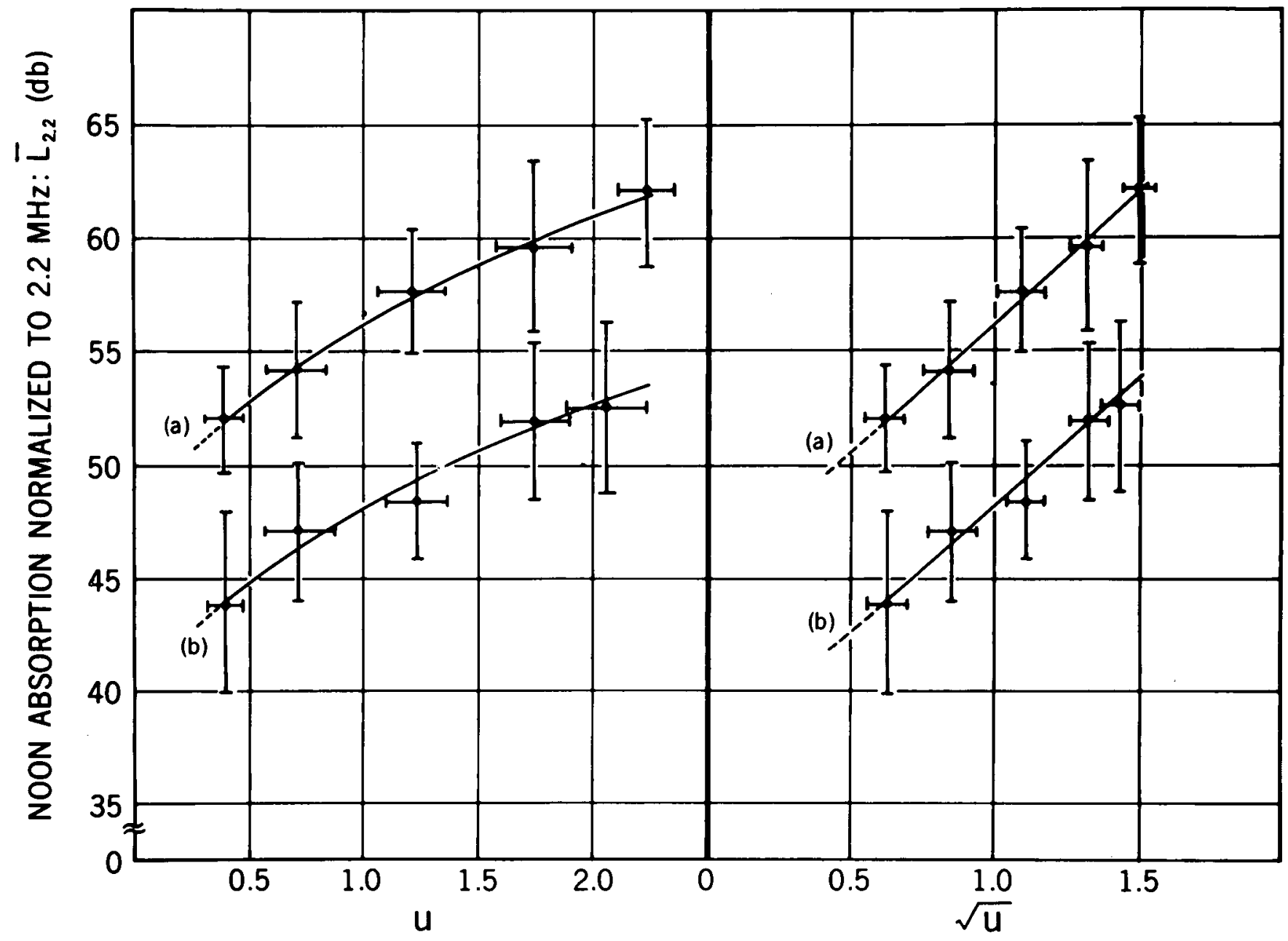

$\mathrm{u}=1-8 \AA$ SOLAR X-RAY FLUX IN MILLIERGS $\mathrm{cm}^{-2} \mathrm{sec}^{-1}$

(a) EQUINOXES (MAR. APR. SEPT. OCT.: $\chi \simeq 10^{\circ}$ )

$\overline{\mathrm{L}}_{2.2}=44.7+(11.5 \pm 0.5) \sqrt{\mathrm{u}} \mathrm{db}$, for $0.4<\mathrm{u}<2.0$

(b) SOLSTICE (DEC. JAN.: $X \simeq 30^{\circ}$ )

$$
\bar{L}_{2.2}=37.0+(11.1 \pm 0.5) \sqrt{u} d b, \text { for } 0.4<u<2.0
$$

FIGURE 5: RELATION BETWEEN ABSORPTION AND 1-8A FLUX FOR MODERATE SOLAR ACTIVITY. 


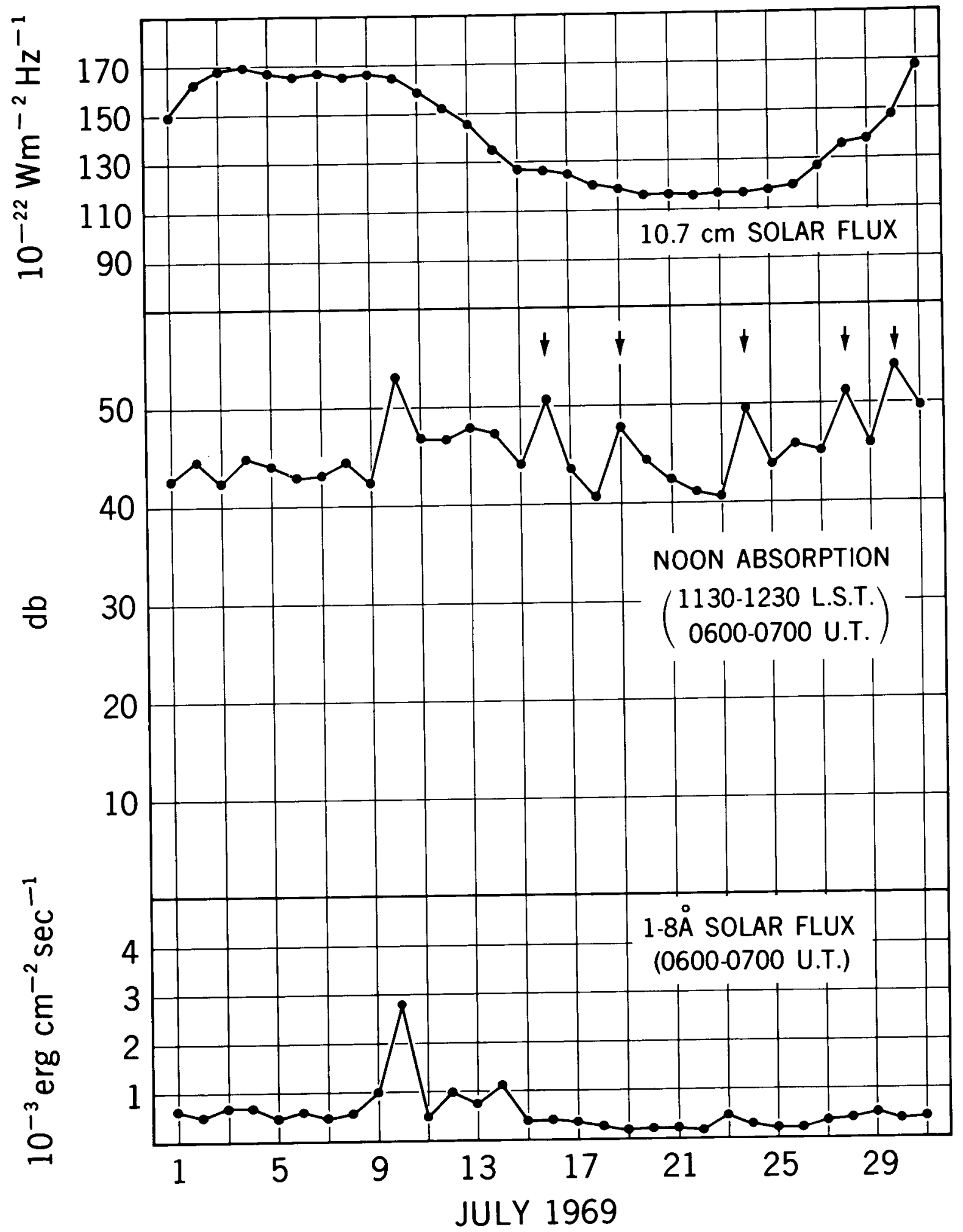

FIGURE 6: ABSORPTION ENHANCEMENTS (INDICATED BY ARROWS) IN THE ABSENCE OF SOLAR X-RAY ACTIVITY 


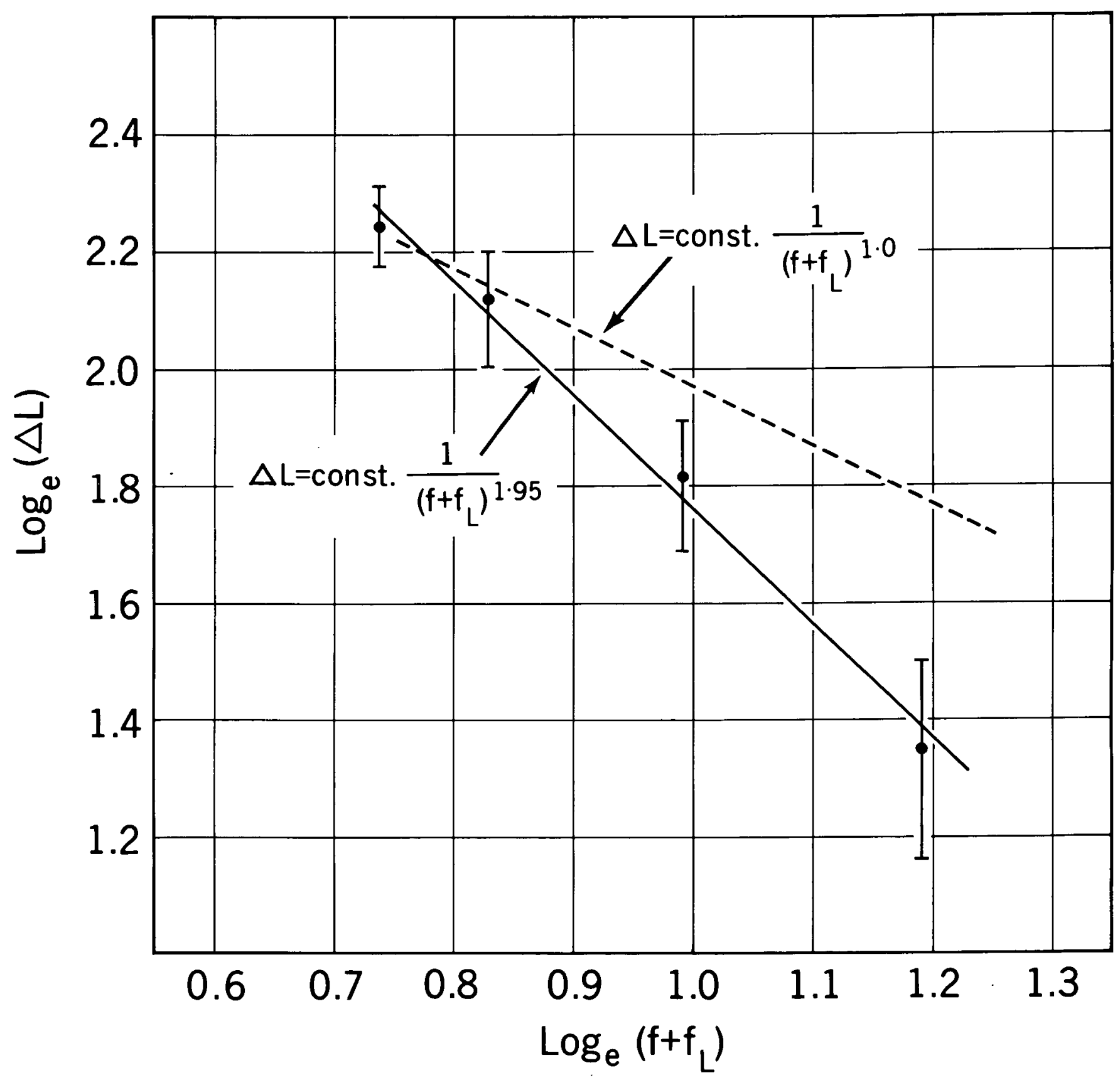

FIGURE 7: INCREMENTAL ABSORPTION AS A FUNCTION OF FREQUENCY 


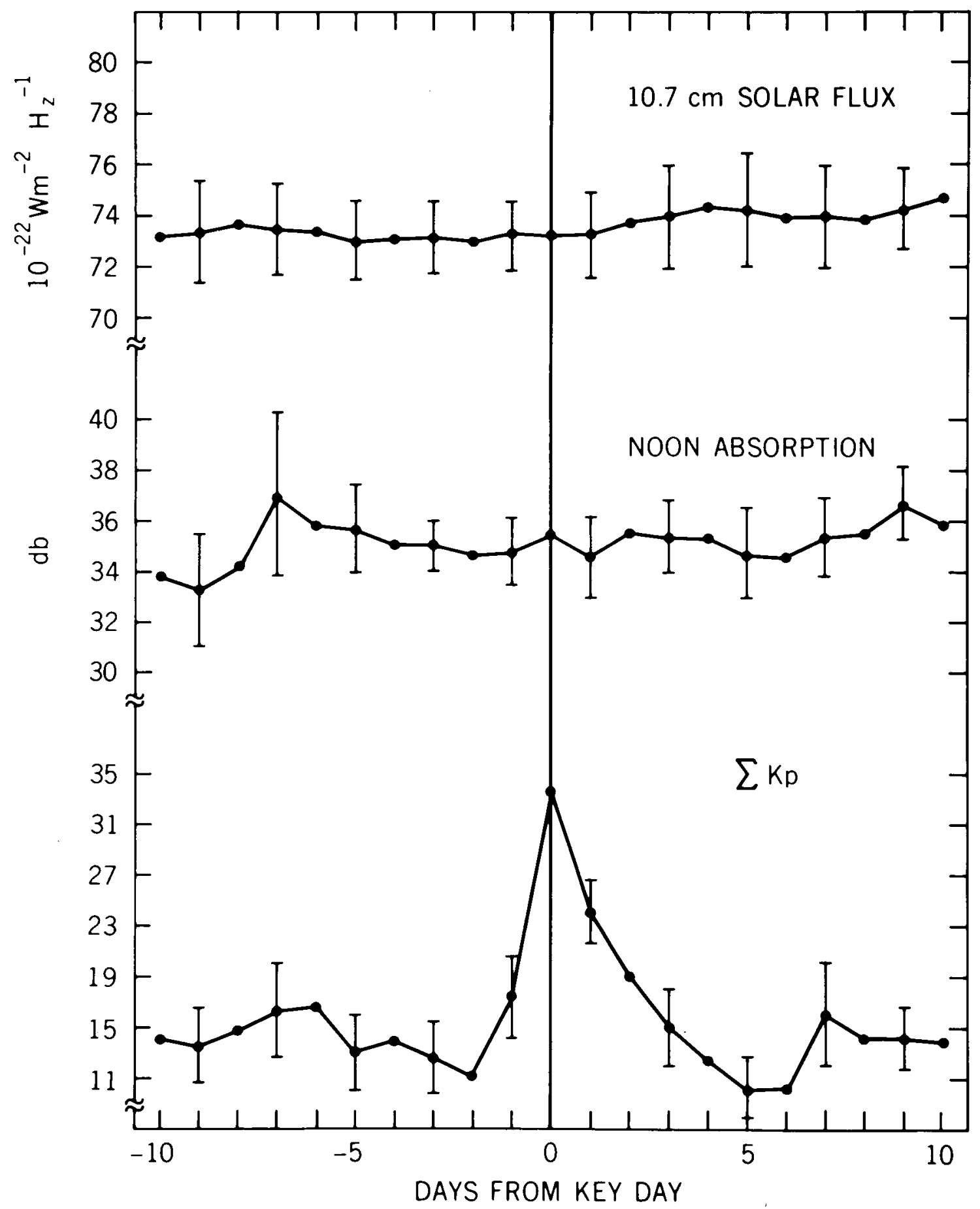

FIGURE 8: RESULTS OF A SUPERPOSED EPOCH ANALYSIS OF 22 MAGNETIC STORMS IN THE SOLAR MINIMUM YEARS 1964 -1965 INDICATING THE ABSENCE OF A SIGNIFICANT MAGNETIC STORM EFFECT ON EQUATORIAL ABSORPTION. THE VERTICAL BARS REPRESENT 95\% CONFIDENCE LIMITS. 


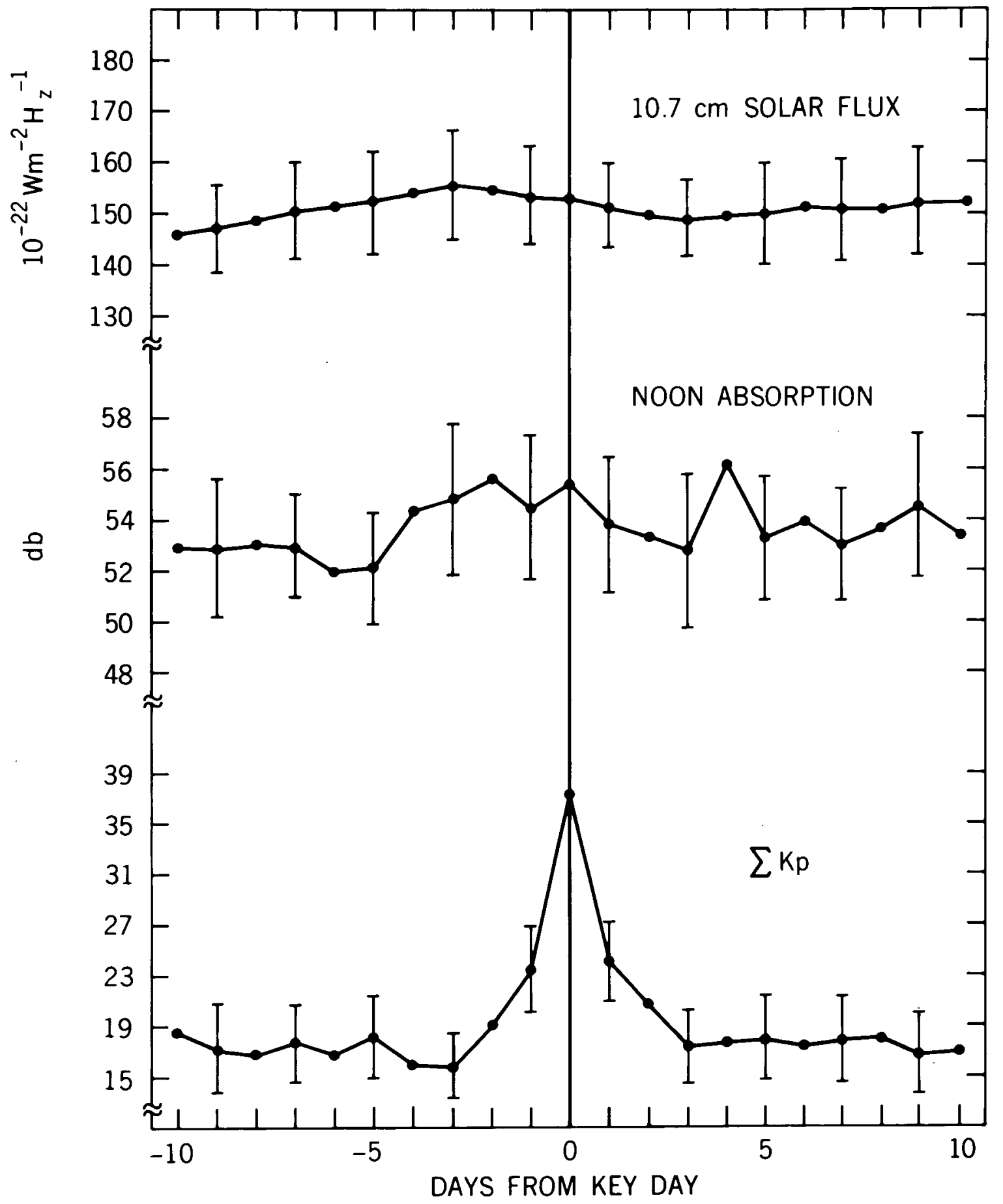

FIGURE 9: RESULTS OF A SUPERPOSED EPOCH ANALYSIS OF 30 MAGNETIC STORMS IN THE SOLAR MAXIMUM YEARS 1968 - 1969 INDICATING THE ABSENCE OF A SIGNIFICANT MAGNETIC STORM EFFECT ON EQUATORIAL ABSORPTION. THE VERTICAL BARS REPRESENT 95\% CONFIDENCE LIMITS. 


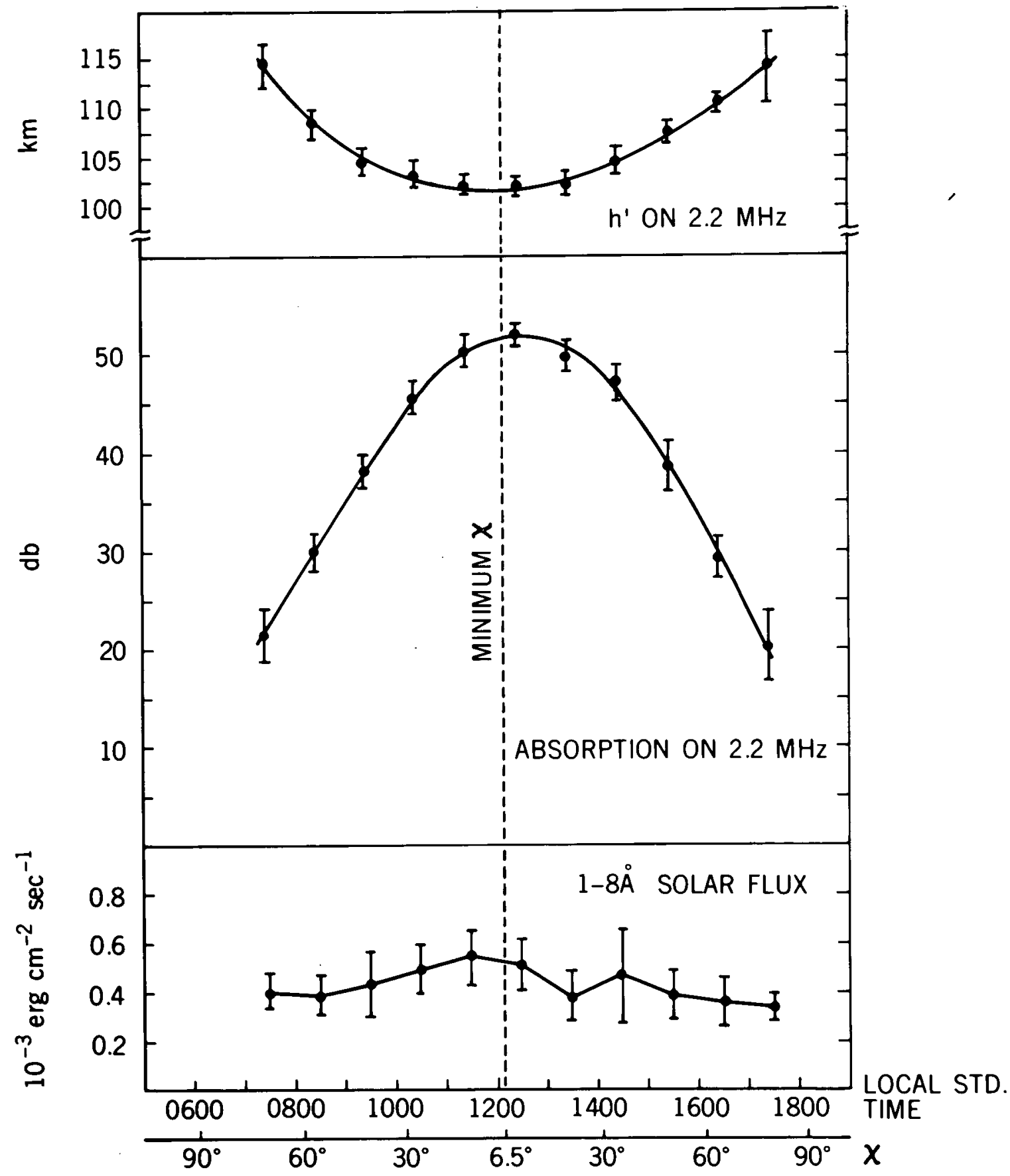

FIGURE 10: MEAN DIURNAL VARIATION OF ABSORPTION AND VIRTUAL HEIGHT ON 15 UNDISTURBED DAYS IN THE EQUINOCTIAL MONTHS OF 1968, 1969 AND 1970. A TIME-DELAY OF 20-30 MINS. IN THE ABSORPTION MAXIMUM WITH RESPECT TO THE TIME OF MINIMUM $X$ IS CLEARLY EVIDENT. THE VERTICAL BARS REPRESENT 95\% CONFIDENCE LIMITS. 


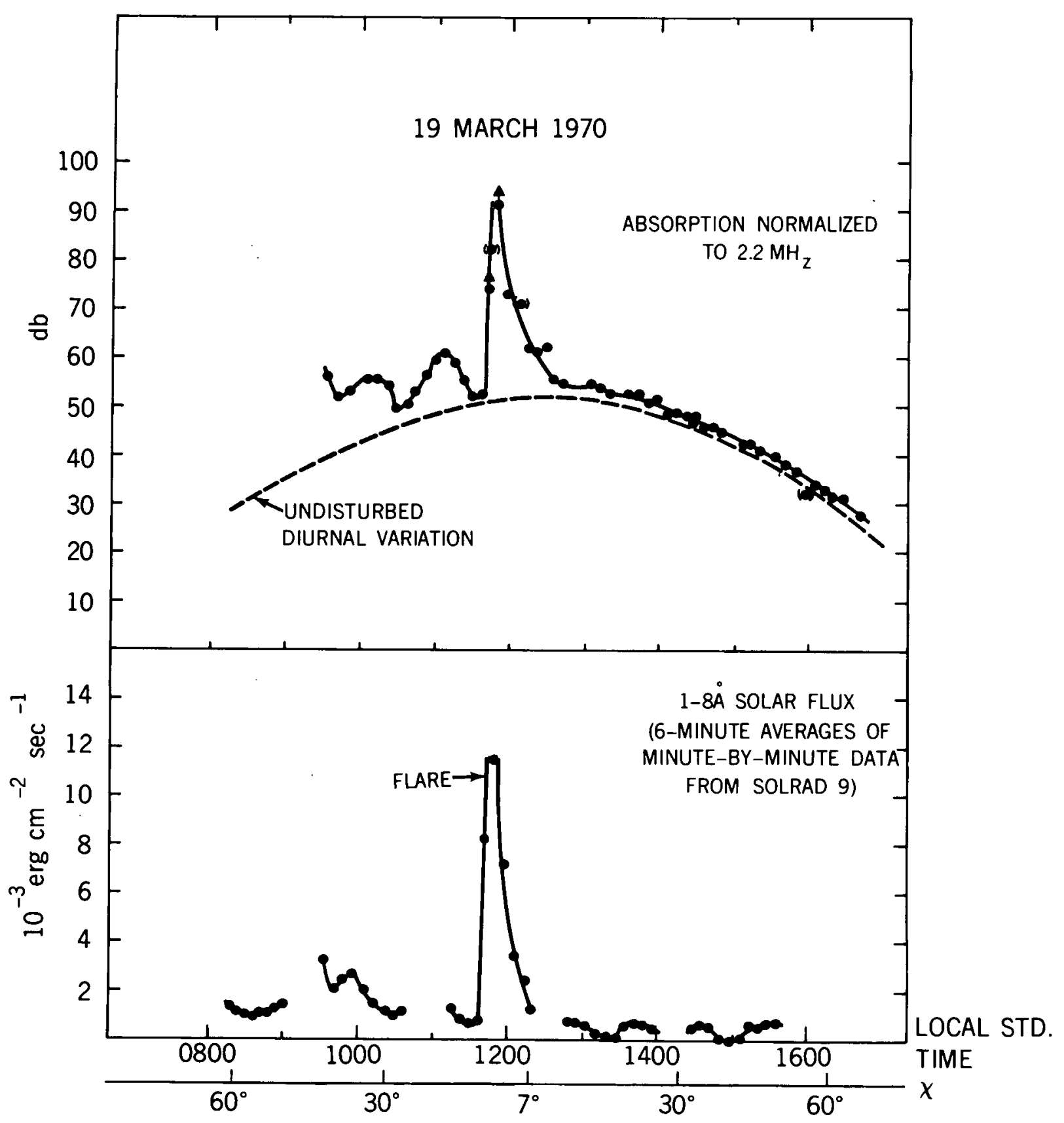

FIGURE 11: DIURNAL VARIATION ON A DISTURBED DAY ILLUSTRATING, IN ADDITION TO THE OBVIOUS FLARE EFFECT, THE CLOSE CORRELATION BETWEEN SHORT-TERM INCREASES IN EQUATORIAL ABSORPTION AND MODERATE ENHANCEMENTS IN SOLAR X-RAY FLUX AT LARGE SOLAR ZENITH ANGLES. 


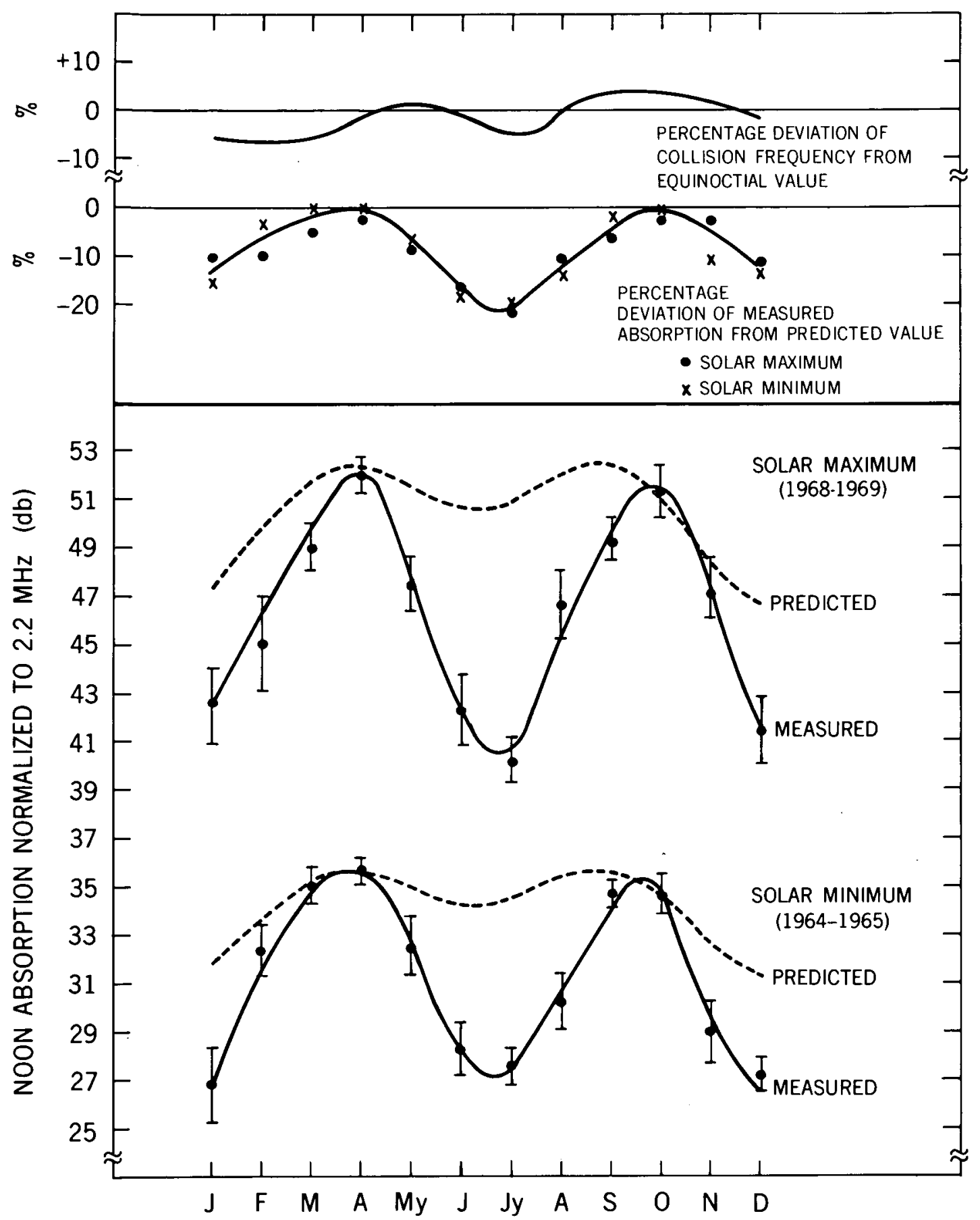

FIGURE 12: SEASONAL VARIATION OF UNDISTURBED NOON ABSORPTION. THE PREDICTED CURVES ARE BASED ON THE ASSUMPTION THAT THE SEASONAL VARIATION FOLLOWS THE SAME SOLAR ZENITH ANGLE DEPENDENCE AS THE DIURNAL VARIATION. THE SEASONAL VARIATION OF THE COLLISION FREQUENCY IS DERIVED FROM THE PRESSURE VALUES OF GROVES (1971) AVERAGED OVER THE ALTITUDE RANGE 85-95KM. AND LATITUDES $0^{\circ}$ AND $10^{\circ} \mathrm{N}$. THE EQUINOCTIAL VALUE OF COLLISION FREQUENCY IS THE MEAN FOR MARCH, APRIL, SEPT. AND OCT. 